\title{
Genealogy, morphology and fitness of spontaneous hybrids between wild and cultivated chicory (Cichorium intybus)
}

\author{
LP Kiær ${ }^{1}$, M Philipp ${ }^{2}$, RB Jørgensen ${ }^{1}$ and TP Hauser ${ }^{3}$ \\ ${ }^{1}$ Biosystems Department, Ris $\varnothing$ National Laboratory, Roskilde, Denmark; ${ }^{2}$ Population Biology Section, Department of Biology, University \\ of Copenhagen, Universitetsparken, Copenhagen, Denmark and ${ }^{3}$ Department of Ecology, Faculty of Life Sciences, University of \\ Copenhagen, Frederiksberg C, Denmark
}

\begin{abstract}
Crop species are known to hybridize spontaneously with wild relatives, but few studies have characterized the performance of hybrids at various genealogies, life stages and environments. A group of cultivar-like individuals and potential hybrids were observed in a roadside population of wild chicory plants in Denmark. Seeds were collected from all reproductive plants and grown in a common garden experiment, and their morphological and genetic compositions were analysed. Intermediate plants were identified as hybrids and comprised various backcross and $F_{n}$ combinations. A genotypic hybrid index $(\mathrm{HI})$, spanning from wild-like to cultivar-like, was highly correlated to a morphological index. Plant survival, growth and reproduction were evaluated and compared to the genotypic HI. Overall, cultivar-like
\end{abstract}

and intermediate plants grew larger than wild-like plants, flowered longer, and produced more flowers and seeds. The common garden included a nutrient gradient. At higher nutrient levels, intermediate and cultivar-like plants produced more flowers and seeds than wild-like plants, whereas this effect was less pronounced at lower nutrient levels. During winter, small rodents consumed roots of cultivar-like and intermediate plants preferentially. Thus, cultivated and wild chicory are able to hybridize spontaneously, producing hybrid offspring of several generations that may reproduce more effectively than their wild parent, but herbivory and poor environmental conditions may negatively affect their fitness. Heredity (2007) 99, 112-120; doi:10.1038/sj.hdy.6800973; published online 2 May 2007

Keywords: crop-wild hybridization; molecular markers; herbivory; hybrid index; soil fertility; vernalization

\section{Introduction}

Domesticated crops often differ in morphology, ecology and physiology compared to the wild species from which they originate. Despite this, almost 80 crop species are currently known to hybridize with weedy and wild relatives (Ellstrand, 2003a), and new examples are continuously added to this list. Hybrids, and their descendants, express a suite of traits inherited from the crop, and they are therefore likely to interact with their biotic and abiotic environment in different ways than co-existing wild-type plants.

Research on hybridization of crops and wild relatives has recently been motivated by concerns about the potential effects of gene flow from genetically modified (GM) crops to wild or weedy relatives (Raybould and Gray, 1994; Conner et al., 2003; Ellstrand, 2003a). Possible impacts of transgenes in wild populations could include increased weediness and invasiveness of wild populations (Ellstrand, 2003b), or impacts could be more indirect, affecting other species in the food web and the evolution of resistance in pest species.

Correspondence: Dr LP Kiær, Biosystems Department, Ris $\varnothing$ National Laboratory, Frederiksborgvej 399, DK-4000 Roskilde, Denmark.

E-mail:lars.kiaer@risoe.dk

Received 15 February 2006; revised 5 November 2006; accepted 16 February 2007; published online 2 May 2007
The potential impacts of GM plants are a subset of the evolutionary and ecological interactions that may arise from hybridization between crops and wild species in general. The actual effects depend on the relative magnitude of incoming gene flow, fitness of the resulting hybrids (of various genealogies) and the effects of specific crop genes included (Zhivotovsky and Christiansen, 1995; Ellstrand, 2003a; Lai et al., 2006).

On one extreme, if the level of crop gene flow is high, small wild populations may become 'genetically swamped' through hybridization, which, combined with outbreeding depression, may result in decreasing population size and local extinction (Rhymer and Simberloff, 1996; Haygood et al., 2003; Ellstrand, 2003b). Hybrids between crops and wild plants can easily be imagined to suffer from maladaptations to living in natural environments due to traits inherited from the crop (Conner et al., 2003); through breeding, crops have been selected for growth in a controlled environment with fewer diseases, herbivores and competitors, and for traits such as lack of seed dispersal and improved palatability. In addition, second and later generation hybrids may suffer from the breakdown of co-adapted gene complexes inherited from their wild parents.

On the other extreme, hybrids between cultivated and wild plants can be more fit than their wild parents (but see Cummings et al., 1999; Hauser et al., 2003; Ellstrand, 2003b; Hails and Morley, 2005; Hooftman et al., 2005; 
Campbell et al., 2006). The first hybrid generations may exhibit heterosis (hybrid vigour) due to increased heterozygosity. Furthermore, novel combinations of genes from the two parental lines could improve their fitness relative to local wild plants (Arnold, 1997; Hauser et al., 1998). The emergence of such transgressive hybrids has been implicated as a major evolutionary mechanism to create novel morphological and ecological traits (e.g. Lexer et al., 2003; and references therein), and weeds and invasive plants may evolve by such novel gene combinations (Ellstrand, 2003a). Eventually, greater fitness of crop-wild hybrids can lead to replacement of local wild plants by hybrid descendants, the process known as genetic assimilation (Haygood et al., 2003; Hegde et al., 2006).

Chicory, a diploid perennial in the Asteraceae, is an economically important vegetable crop with many commercially available cultivars, including in recent years transgenic cultivars (e.g. http://www.agbios. com/dbase.php) (Ryder, 1999; Kiers, 2000). Although chicory is not on Ellstrand's (2003a) list of hybridizing crop species, several lines of evidence suggest that spontaneous hybridization with wild plants is likely. Wild chicory grows throughout Europe and much of North America; chicory is also cultivated commercially in these regions (Ryder, 1999). Cultivated chicory not only flowers during seed propagation (Ryder, 1999), a proportion of plants may also flower as bolters during vegetative production (Schittenhelm, 2001). Furthermore, chicory is almost obligately outcrossing due to an effective self-incompatibility system (Eenink, 1981), and it is insect pollinated. Hybridization between cultivated and wild chicory was implicated by Rick (1953), who described hybridization between chicory and a wild relative, endive (Cichorium endivia) as a problem for commercial seed growers in California. A theoretical review classified chicory hybrids as 'possible' in nature (de Vries et al., 1992).

In this study, we tested the genetic and morphological composition of potential hybrids between cultivated and wild chicory. Within a roadside population of wild chicory near Roskilde, Zealand, Denmark, a group of individuals that looked exactly like leaf-type cultivar plants were observed: their leaves were unindented, light green, wide, obovate to elongate and erect (Kiers, 2000). These traits are never observed among wild chicory plants in Denmark; other roadside plants distant from these looked like ordinary wild chicory, with horizontal and deeply incised, dark green leaves (Frederiksen et al., 2006). Close to the cultivar-like plants grew a number of individuals with an intermediate morphology, suggesting that they could be hybrids. In a cluster analysis based on AFLP (amplified fragment length polymorphism) genetic markers, the cultivar-like plants grouped with the 'Pan du Sucre' (leaf type) cultivar type, and the wild-like plants grouped with other wild Danish populations (unpublished data).

From this, population seeds were harvested and offspring plants were grown in an experimental plot. Using morphological traits and molecular marker analysis, we investigated if the offspring plants were indeed hybrids, and if so, how many generations of spontaneous intercrossing had occurred between the cultivar and wild plants in the roadside population. We further aimed to determine whether the potential hybrid plants survived and reproduced more or less successfully than the cultivar and wild-like plants, and to what extent their fitness varied.

\section{Materials and methods}

\section{Plant material}

The roadside population, at the time of our seed harvest, contained 31 wild-like and intermediate chicory plants and 30 cultivar-like plants. Of these, we could harvest seeds from 13 plants. More plants had probably flowered earlier and most likely fathered some of the seeds, but were then cut down as roadsides in Denmark are mowed occasionally. We numbered the harvested seed families 1-13 according to the mother's distance from the group of cultivar-like plants (family 1, $5 \mathrm{~m}$ from cultivar-like plants; family 13, $200 \mathrm{~m}$ ).

Seeds were germinated in trays filled with a commercial soil mix within a greenhouse, and seedlings were vernalized outdoors under natural winter and spring regimes to induce flowering (Harrington et al., 1959). Offspring families were raised in three cohorts with different starting dates for vernalization (2500, 1400 and 600 cumulative hours, respectively, at temperatures below $10^{\circ} \mathrm{C}$; Wiebe, 1997). Following vernalization, 588 plants with approximately even representation of maternal offspring families and vernalization cohorts were transplanted into a field plot at Ris $\varnothing$ National Laboratory, Roskilde, Denmark. The plot comprised six double rows with 49 plants in each row, with plants from each family and cohort distributed randomly within and between double rows. Neighbouring plants were $30 \mathrm{~cm}$ apart; distance between double rows was $100 \mathrm{~cm}$.

The plot included a gradient of nutrient levels. Twelve soil cores were taken from each of four transects running along the rows, and analysed for $\mathrm{pH}$, phosphorous and potassium (by Steins: http://eng.steins.dk/index.asp). Phosphorous and potassium increased linearly along the rows (P: $3.0-4.2 \mathrm{mg} 100 \mathrm{~g}^{-1}, R^{2}=0.86$; $\mathrm{K}: 16.7-24.5 \mathrm{mg}$ $100 \mathrm{~g}^{-1}, R^{2}=0.87$ ) and $\mathrm{pH}$ decreased linearly (from 7.8 to 7.6, $\left.R^{2}=0.90\right)$

To evaluate whether plants were parent-like or hybrids, a subset of 260 plants was selected for studies of morphology, genotype and reproduction; all plants were monitored for flowering period and herbivory (see below). The subset was distributed as evenly as possible among offspring families, vernalization cohorts and positions in the field plot.

\section{Morphology}

Five leaf traits were scored visually on the 260 plants: proportion of leaf edge indented, indention depth, ration of length to width, erectness and colour. For each trait, individual plants were assigned a value from one (completely wild-like) to five (completely cultivar-like). To minimize the effects of scoring bias, plants were independently scored by five persons so that each plant was assigned a total of 25 scores.

\section{Genetic markers}

From the same plants that were scored morphologically, fresh tissue was collected for AFLP analysis. Tissue was also sampled from 24 of the pure cultivar-like plants from the roadside population, and from five individuals 
belonging to a wild population a few kilometres away. DNA was extracted from freeze-dried and ground tissue following the CTAB-based procedure of Doyle and Doyle (1987) with minor modifications: active carbon and mercaptoethanol was added to the CTAB buffer before extraction ( $5 \mathrm{mg}$ and $3 \mu \mathrm{l}$ per $\mathrm{ml}$, respectively); samples were treated with RNAse before isopropanol precipitation; pellet isolation and resuspension following precipitation was omitted; and the samples were stored at $-20^{\circ} \mathrm{C}$ until use. The AFLP procedure was performed according to Vos et al. (1995) with modifications as described by Johannessen et al. (2002) and Shim and Jørgensen (2000). Specific amplification was carried out using the primer combinations EcoRI +CAC/ $\mathrm{Mse}$ I + AGG and EcoRI + CAG/MseI + AGG. The amplified DNA samples were mixed with $98 \%$ formamide loading buffer, heated at $96^{\circ} \mathrm{C}$ for $5 \mathrm{~min}$ and quickly cooled on ice. These samples were loaded for separation of DNA fragments on a $5 \%$ denaturing polyacrylamide long-range gel on an LI-COR 4200 series Automated DNA sequencer. For some of the samples we were unable to obtain meaningful banding patterns and excluded those from further analyses. Useful markers were found within the $90-300 \mathrm{bp}$ range, using Kodak 1D (version 3.6, 2002; Kodak Scientific Imaging Systems, New Haven, CT, USA), and bands were scored as 1 (present) or 0 (absent). Each band was considered a putative locus, representing its dominant genotype, and markers with band frequencies above 0.95 and below 0.05 were omitted.

\section{Fitness traits}

The dates of flowering initiation and termination were recorded for all plants. Flowering ended in October due to short days and low temperatures. The following traits were measured on the subset of 260 offspring plants (scored morphologically and genetically): height and dry weight of the flower; root size, estimated based on the square of root diameter at ground level; the number of capitulae per plant; and the number of seeds per capitulum (average of three randomly chosen capitulae per plant). The total number of seeds per plant was estimated as the product of the latter two. Seed viability was tested on a subset of 20 plants chosen to capture the range of offspring families and genotypes, by measuring the proportion of germination on moist filter paper in Petri dishes under repetitive climate cycling (12 h light/ $22^{\circ} \mathrm{C}, 12 \mathrm{~h}$ darkness $/ 11^{\circ} \mathrm{C}$ ).

After harvest, the plot was left unmanaged for later analyses and observations. During the following winter, small rodents consumed some chicory taproots. To study whether or not herbivory preferentially affected certain genotypes of plants, we recorded if the upper growth meristem and the central taproot were gone and the plant therefore was dead. This was carried out for the full set of plants in the experiment.

\section{Data analyses}

The genetic and morphological variation among individuals was visualized by principal coordinate (PCO) analyses, using pair-wise mean character difference and Euclidean distances between individuals, respectively. Both analyses were performed with the freeware Ginkgo (http://biodiver.bio.ub.es/vegana/).
A morphological index value and a genotypic hybrid index (HI) value were assigned to each plant in the subset used for fitness analyses. According to Spearman's rank correlation tests for non-parametric data (with $t$-approximation and correction for ties), the scores were consistent among the five persons (all pair-wise correlations: $P<0.001$; Spearman's $r$ between 0.75 and 0.84) and the morphological traits were mutually correlated (all pair-wise correlations: $P<0.001$ ). Hence, the average of the 25 scores of each plant was used as its morphological index value. The genotypic HI was based on an assignment test for binary data, using AFLPOP software for population assignment based on dominant markers (Duchesne and Bernatchez, 2002). The likelihood that each offspring individual derived from the group of cultivar-like plants in the roadside was estimated from its multi-locus genotype and the allele frequencies in that cultivar-like group. This assignment likelihood was used directly as its genotypic HI value. Initial analyses, using $t$-tests and correlations, showed that alternative hybrid indices based on assignments to other potential source populations, and differences in assignment compared to the one used, provided similar results (all $P<0.01 ; 0.73<R^{2}<0.90$ ). These populations included the distant wild population and the group of roadside plants indicated by morphology and NewHybrids software (see below) to be pure wild. However, all of the alternative indices were based on the assumption that the wild 'source' population was similar to those in the original wild population before cultivar plants were sown or planted out, which may not be true.

To determine whether plants with intermediate $\mathrm{HI}$ values were indeed hybrids, we used the software NewHybrids (Anderson and Thompson, 2002). This method requires no prior information on genetic composition of the parental populations, but assigns individuals to putative populations based on minimization of departures from Hardy-Weinberg and linkage equilibrium. As chicory is self-incompatible, populations at equilibrium would be expected to mate randomly. The method can further assign individuals to a number of hybrid classes (pure population 1, pure population 2, first generation hybrids $\left(F_{1}\right)$, second generation hybrid $\left(F_{2}\right)$ and $F_{1}$ backcrossed to either population (BC-P1 and $\mathrm{BC}-\mathrm{P} 2$, respectively), using Markov chain Monte Carlo simulations to estimate the posterior probability that each individual belongs to each of the classes. We used the software to test whether the cultivar- and wild-like plants indeed formed two different groups (without including prior information about the cultivar-like plants in the roadside), and to determine the most likely genealogical class of the genotyped plants. We used non-informative Jeffrey priors and ran the analyses for 20000 iterations (2000 iterations burn-in). Each result was checked by comparing several runs with a pair-wise t-test, which showed significant similarity in each case.

Correlation between the morphological index and genetic HI was tested with a $10^{5}$ permutations Mantel test based on two matrices of pair-wise distances (mean character difference) between individuals. Similarly, a $10^{5}$ permutations Mantel test was used to compare distance matrices based on markers from the two AFLP primer combinations.

The following fitness traits were tested against the genotypic HI of the individual: biomass of above-ground 
parts, flower stem height, root size, root-to-shoot ratio (root size relative to above-ground biomass), flowering termination date, flowering length, capitulae per plant, seeds per capitulum and estimated seed set per plant. All fitness estimates were based on plants from all vernalization treatments, and observations were log-transformed before analysis. After preliminary exploration and tests on data, linear regression models (S-PLUS, version 6.1, 2002. Insightful Corporation, Seattle, WA, USA) were chosen for these tests.

The probability of flowering and the degree of herbivory in relation to $\mathrm{HI}$ were tested by logistic regression (logit-link) and $\chi^{2}$-test (S-PLUS, 2002). The proportion of herbivory in each family was tested against the average $\mathrm{HI}$ value of the family, as not all plants in the field plot were genotyped.

The effect of the nutrient gradient in the plot was tested by including the plants position along rows in the regression analyses of fitness traits. Genotypes apparently responded similarly to the gradient with respect to all traits (no significant interactions with plot position). However, some of the interactions were close to significant (root size: $P=0.14$; biomass: $P=0.1$ ). For a more detailed analysis of possibly undetected interactions, we therefore divided the plants into three groups based on their genotypic HI value: wild-like (HI values of -52.7 to -42.1 ); intermediate (HI values of -42.1 to -31.6); and cultivar-like (HI values of -31.6 to -21.0 ). The performances of these groups along the gradient were then compared by testing for equal slopes of the linear regressions of fitness traits on plot position.

The possible effect of competition from neighbouring plants was tested by including the average HI values of neighbouring plants in additional regressions of each fitness trait against the HI. We found no effect on any of the examined fitness traits (results not shown).

\section{Results}

\section{Morphological traits}

Offspring harvested from mothers growing closest to the cultivar-like group of plants in the roadside (lower numbered families) were more cultivar-like in morphology than offspring from mothers further away (higher numbered families) (Figures $1 \mathrm{a}$ and 2a). Offspring from mother plants farthest away from cultivar plants (10-13) had conspicuously wild-like leaves. Intermediate plants were much more variable in morphology than the more wild- or cultivar-like (Figures 1a and 2a).

\section{Genetic markers}

The two primer combinations yielded a total of 109 polymorphic bands. The two combinations resulted in similar pair-wise distances between individuals (Mantel test; $P<0.001$ ). PCO analysis (based on genetic distance) and $\mathrm{HI}$ values (based on assignment) both showed that offspring from families 1-7 were relatively similar to the cultivar-like plants from the roadside, whereas offspring from families 10-13 were most different from these (Figures $1 \mathrm{~b}$ and $2 \mathrm{~b}$ ). Offspring from families 8 and 9 were clearly intermediate. Analysis of genealogy, using NewHybrids, corroborated these results. Most of the individuals in families 1-6 assigned to one population, the individuals in family 7 assigned to the same population
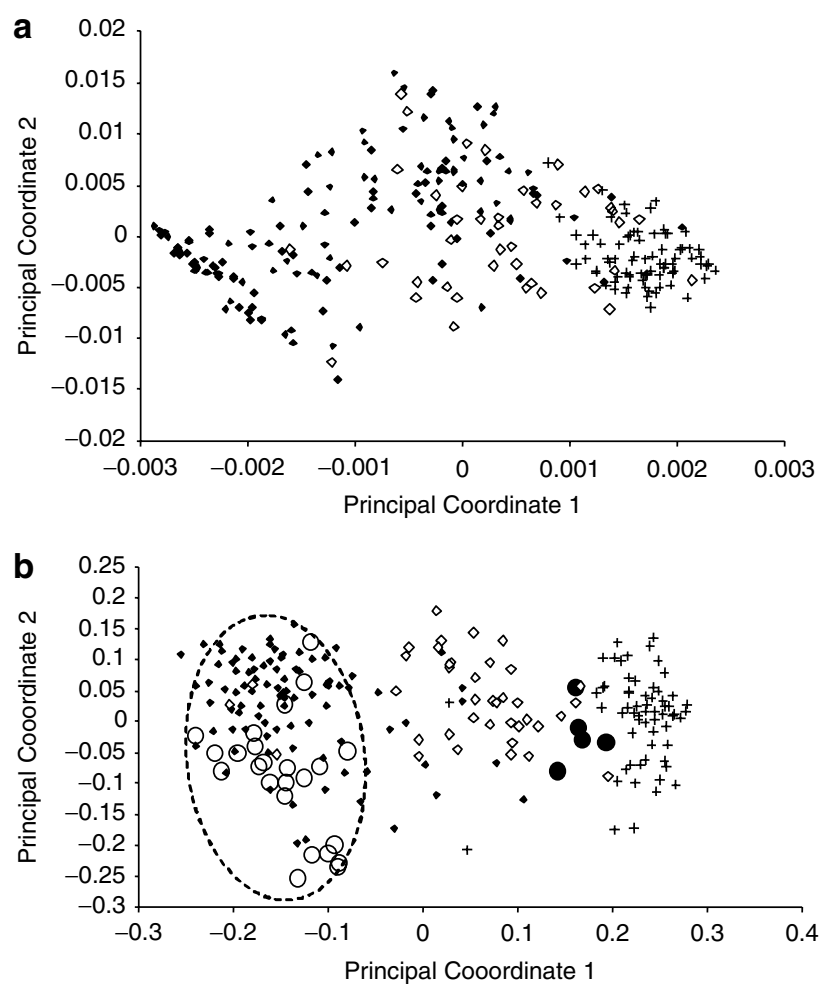

Figure 1 Principal coordinate analysis of (a) morphological distances between offspring individuals (families 1-7: full diamonds; families 8 and 9: open diamonds; families 10-13: crosses) and (b) genetic distances (as above; in addition: cultivar individuals from the roadside (open circles) and individuals from another wild population (full circles)). The broken line oval in (b) demarcates the distribution of cultivar individuals.

or backcrosses to it, families 8 and 9 were distributed mainly over the four hybrid classes and families 10-13 assigned mostly to a different population (Figure $2 b$ ).

The genotypic HI values were highly correlated with the morphological index values $\left(R^{2}=0.603 ; P<10^{-15}\right)$, and the indices resulted in similar matrices of pair-wise distances between individuals (Mantel test; $P<0.001$ ).

\section{Biomass and size}

All plants, except one, survived to the time of flowering. Overall, cultivar-like plants were taller, weighed more, and had larger roots and shoot-to-root ratios than wildlike plants (Table 1 and Figure 3 ). Intermediate plants were as large as cultivar-like plants (height: $P=0.992$; weight: $P=0.118$; and root diameter: $P=0.758$, respectively) and larger than wild-like plants $\left(P<10^{-5}\right.$, $P<10^{-13}$ and $P<0.001$, respectively; Figures 3 and 4$)$.

Response to the nutrient gradient was evident in all three plant groups (see above; $0.05<P<10^{-5}$; Figure 4 ac). Intermediate and cultivar-like plants responded similarly to the increasing nutrient levels and had greater biomass at the most nutrient-rich end of the plot compared to the nutrient-poor end (test for equal slopes: $P=0.887$; Figure 4a). Wild-like plants differed from these (rejection of equal slopes: $P<0.05$ ), with a much lower biomass than cultivar-like and intermediate plants at the most nutrient-rich end of the plot and a somewhat, but significantly, lower biomass at the nutrient-poor end 

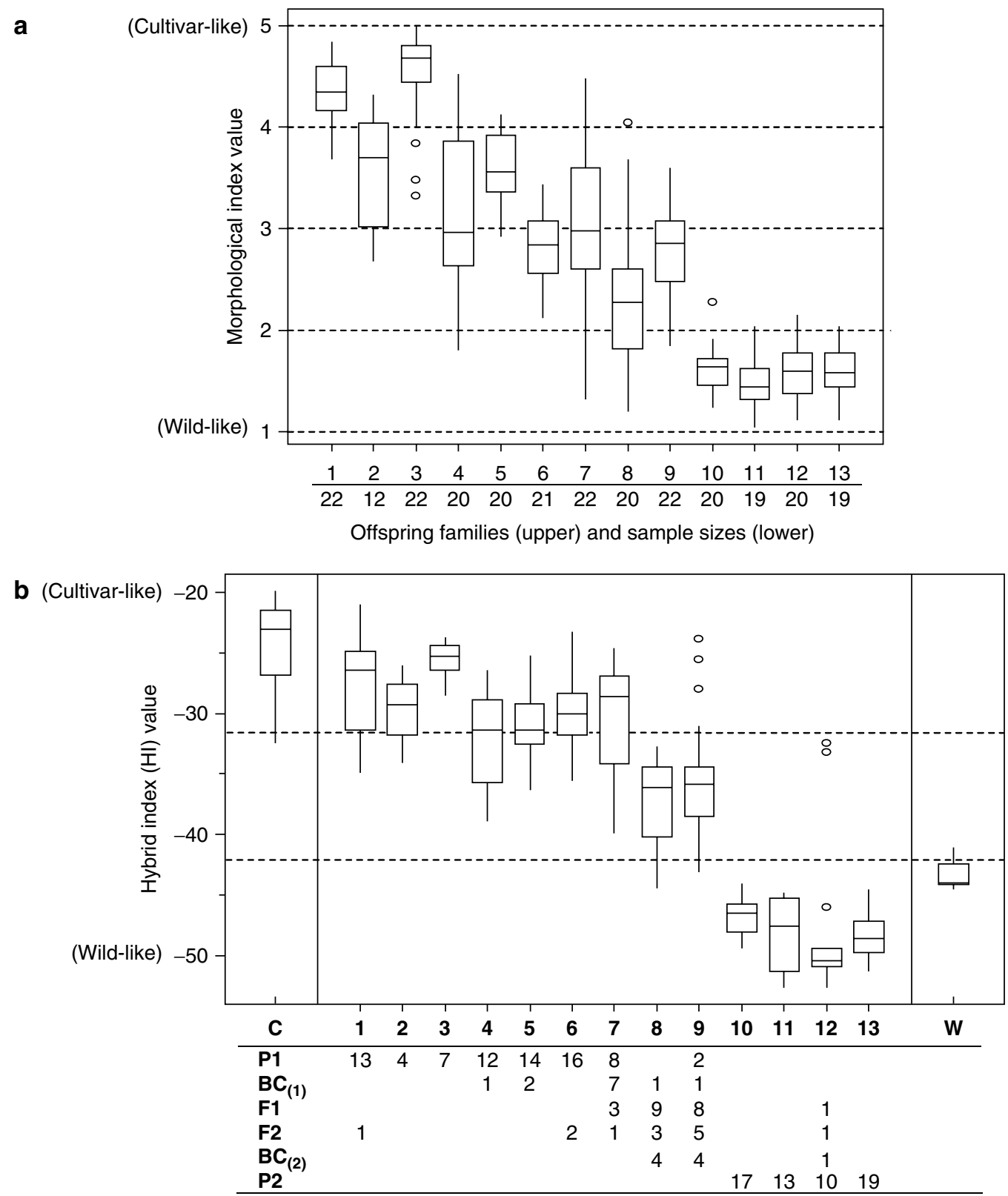

Offspring families and reference groups (top row)and genealogical distributions (other rows)

Figure 2 Distributions of (a) morphological hybrid index (HI) values and (b) genotypic HI values and estimated genealogies within each offspring family (1-13). (a) A value of one indicates completely wild-like morphology, and a value of five indicates completely cultivar-like morphology. (b) High (least negative) HI values indicate high similarity to the cultivar-like plants from the roadside, the HI distribution of which is shown for comparison (C); the HI distribution of individuals from a neighbouring wild population is also shown (W). The broken horizontal lines demarcate the HI ranges used to group offspring in three (see Materials and methods). Boxes present the median (central horizontal line), 25 and 75\% quartiles (lower and upper edges of the box) and range of estimated normal distribution (vertical lines). Outliers (empty circles) are included. Below the box-plot is shown the distributions of most likely genealogies for the offspring in each family, as assigned by the software NewHybrids.

(Figure 4a; $t$-tests of data from position classes $5-7$ : $P<0.001)$.

\section{Flowering}

Of the 260 genotyped plants, $63 \%$ flowered. The probability of flowering was lower after a short cold treatment than after medium or long treatment $(54,93$ and $87 \%$, respectively; $\chi^{2}$-test; $P<10^{-15}$ ).

Cultivar-like and intermediate plants flowered longer than wild-like plants (Table 1), but initial flower- ing dates were similar (data not shown). Plant position had no effect on flowering period (data not shown) but affected the probability of flowering, which was greater towards the most nutrient-rich end of the plot $(P<0.01)$.

\section{Seed set}

Overall, cultivar-like plants produced more capitulae than wild-like plants (Table 1), and the number of 
Table 1 Regression of fitness trait estimates (log-transformed) against genotypic hybrid index values

\begin{tabular}{lcccl}
\hline Fitness trait & Sample size & $\mathrm{R}^{2}$ & P-value & Slope direction \\
\hline Above-ground biomass & 163 & 0.257 & $* * *$ & Cultivar $>$ wild \\
Flower stem height & 163 & 0.313 & $* * *$ & Cultivar $>$ wild \\
Root size & 163 & 0.132 & $* * *$ & Cultivar $>$ wild \\
Shoot to root & 163 & 0.123 & $* * *$ & Cultivar $>$ wild \\
Flowering termination & 161 & 0.245 & $* * *$ & Cultivar $>$ wild \\
Flowering length & 161 & 0.259 & $* * *$ & Cultivar $>$ wild \\
Capitulae per plant & 161 & 0.377 & $* * *$ & Cultivar $>$ wild \\
Seeds per capitulum & 161 & & NS & Cultivar $=$ wild \\
Seeds per plant & 161 & 0.365 & $* * *$ & Cultivar $>$ wild
\end{tabular}

For each dependent fitness trait is showed the sample size, explanatory power, significance level $(* * * P<0.001)$ and direction of the regression slope (wild versus cultivar). Sample sizes vary because two plants produced only flower stem but no flower buds.

capitulae per plant correlated with the flowering length $\left(R^{2}=0.33 ; \quad P<10^{-15}\right)$. There were no differences in number of seeds per capitulum between plant types, and accordingly, cultivar-like plants produced more seeds in total than did wild-like plants (Table 1; Figures $3 \mathrm{e}$ and $4 \mathrm{e})$. Intermediate and cultivar-like plants produced more seeds in the more nutrient-rich end of the plot (compared to the end with least nutrients; linear regressions; $P=0.019$ and $P<0.010$, respectively; test for equal slopes; $P=0.98$ ), whereas wild-like plants did not differ in this respect (linear regression; $P=0.16$ ). Even in the more nutrient-poor end of the plot, intermediate and cultivar-like plants produced more seeds than wild-like plants ( $t$-tests of data from position classes 5-7: $P<10^{-4}$ and $P<10^{-3}$, respectively) (Figure $4 \mathrm{e}$ ).

Seeds produced by wild-like, intermediate and cultivar-like plants did not differ in germination proportions $\left(R^{2}=0.017 ; P=0.46\right)$.

\section{Herbivory}

The taproots of 22 plants were consumed by small rodents during the winter, and 21 of these had not flowered. As families varied in their proportion of nonflowering plants, the rates of herbivory were weighted according to this in the analysis. Cultivar-like plants were eaten more frequently than wild-like plants $\left(P<10^{-15}\right.$; Figure 5$)$, and in some families, more than $50 \%$ of the plants that had not flowered died.

\section{Discussion}

Hybridization of wild and cultivated chicories

Morphological and genetic analyses showed that the plants in our experiment included individuals representing the continuum from wild-like chicory, through intermediate hybrids, to cultivar-like chicory, results consistent with our observations of the roadside population. Thus, chicory may now be added to the list of crop species known to hybridize spontaneously with wild relatives.

Based on a genetic model of hybridization (NewHybrids), the selected plants formed two pure populations and a large number of hybrid plants. Notably, the intermediate plants were assigned to both the $F_{1}$ and second generation crosses $\left(\mathrm{F}_{2}\right.$ and backcrosses to each
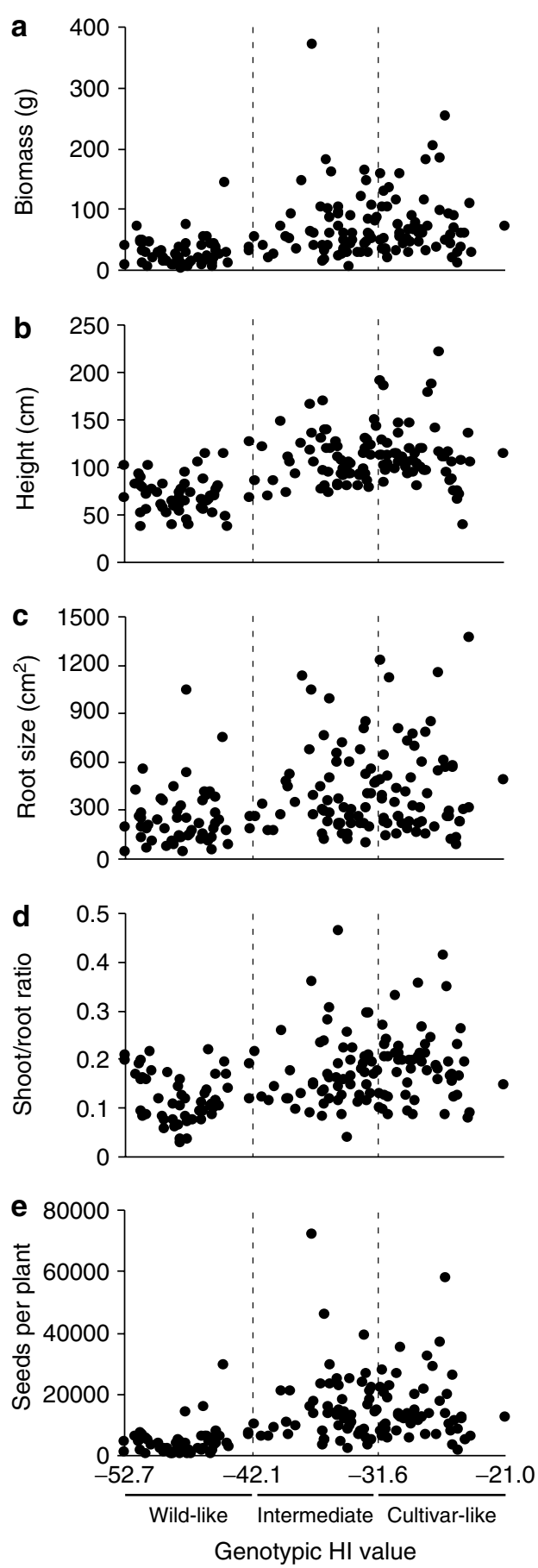

Figure 3 (Left column of displays) Fitness estimates of individual offspring plants plotted against their genotypic HI value. Broken lines demarcate the genotypic ranges used to divide the plants into wild-like, intermediate and cultivar-like groups for the analysis of fitness components in relation to plot position (see Materials and methods)

parental population). As the assignment to genealogical classes in NewHybrids was limited to the second intercrossing population, some of the plants may in fact be of a later, more advanced genealogy. However, identification of intermediate hybrid genotypes was achieved with higher statistical confidence than demon- 
a

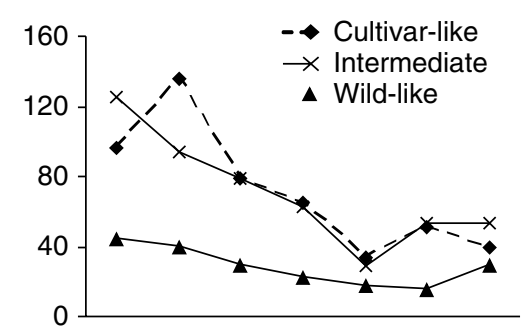

b

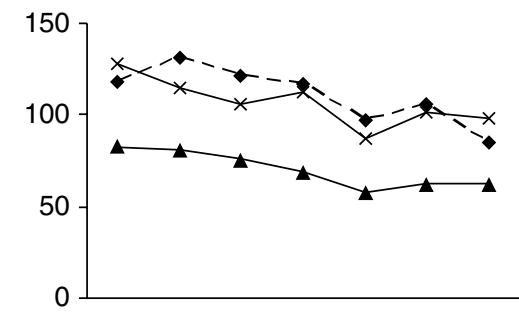

C

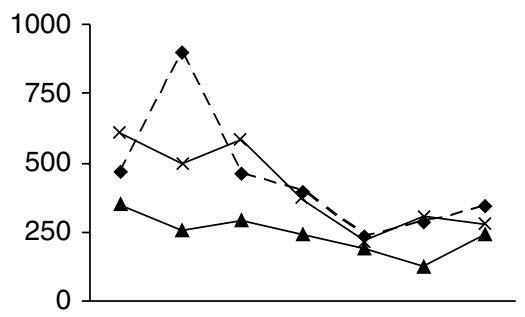

d
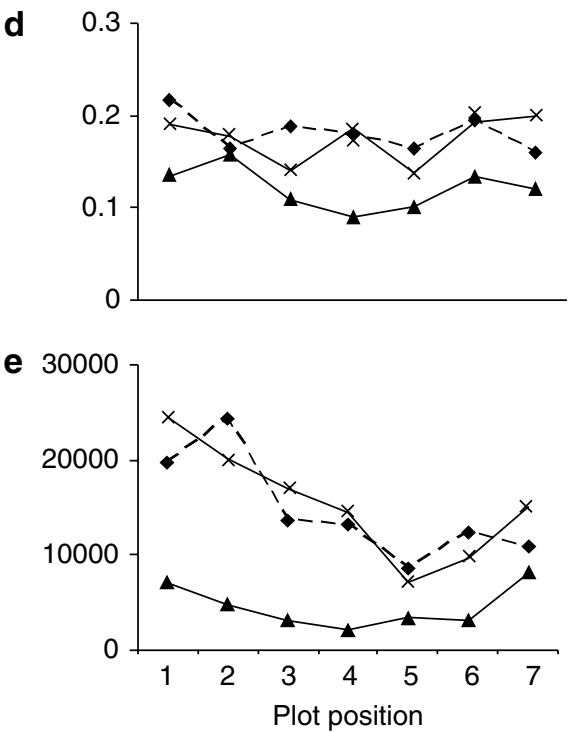

Figure 4 (Right column of displays) Mean fitness estimates of the cultivar-like, intermediate and wild-like groups as a function of their position along plot rows (depicted as seven position classes). The levels of potassium and phosphorous were highest towards position 1 , and lowest for $\mathrm{pH}$.

stration of backcrossing to wild populations. Sampling of a larger number of markers to improve genomic coverage and a larger number of well-defined wild populations would improve our ability to detect introgression with confidence.

Morphologically, the hybrid plants in our experiment were extremely variable, and many plants had novel combinations of traits not previously observed in wild or

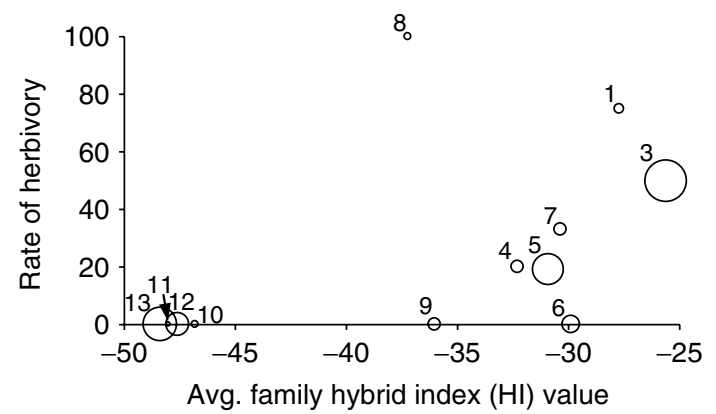

Figure 5 Ratio of plants eaten to the number of plants that did not flower in each plant family (in \%), plotted against mean family genotypic HI values. Diameters of circles reflect the proportion of plants in the family that had not flowered that year, the largest proportion being found in family $3(44 \%)$ and the smallest in family $8(4 \%)$. Family 2 is not visible in the plot, as all plants in the family flowered and none was eaten.

cultivated populations (Figure 1a). This is indicative of hybrids past the first hybrid $\left(\mathrm{F}_{1}\right)$ generation, with recombination events bringing together new combinations of genes contributing to leaf morphology. Such transgressive variants may form the starting material for evolution of new hybrid lineages as shown in hybrid species of sunflower (Lexer et al., 2003). In chicory, leaves of leaf-type cultivars and wild Danish plants are very different, with the broad non-indented leaves used for salad being selected by breeders from wild chicories at some time in the past. De Vries et al. (1992) concluded that hybrids between wild and cultivated chicory are 'difficult to distinguish' and therefore 'undetectable.' Our results show that this is certainly not always the case.

\section{Resource utilization and allocation}

The larger size and greater reproductive output of intermediate plants, as compared to wild-like plants, were most pronounced at the end of the plot with relatively high levels of phosphorous and potassium and low $\mathrm{pH}$, but also evident at the end of the gradient with least nutrients and highest $\mathrm{pH}$. Notably, the intermediate plants behaved more or less like the cultivar-like plants. Breeding and cultivation of chicory cultivars under intensive cultivation has perhaps selected plants that are more responsive to high nutrient concentrations. Hybrids between wild and cultivated chicory seem to have inherited this trait, as may be the case for wildcultivar hybrids of other crops species as well (Hauser et al., 2003).

Compared to wild-like plants, the intermediate plants invested relatively more of their resources in vegetative and reproductive growth than in storage, as indicated by higher shoot-to-root ratio. This resource allocation is likely inherited from the leaf-type cultivar, which has been selected towards a one-year growth pattern in which increase in harvestable biomass is favoured over storage and survival. Similar differences between wild, cultivated and hybrid plants in allocation to first year reproduction versus storage have been described for carrot (Hauser and Bjørn, 2001) and beet (Van Dijk, 2004). The ability to flower in the first year of growth allows 
hybrids of these species to reproduce in the field before root harvest and thereby initiate weedy hybrid populations. It is possible that a similar shift in allocation exists for chicory.

\section{Reproductive output}

The larger numbers of seeds produced by cultivar-like and intermediate plants as compared with wild plants resulted from larger numbers of capitulae, which were correlated with longer flowering periods. The number of capitulae per plant was previously identified as the principal component of seed yield differences in cultivated chicory (Fanizza and Damato, 1995). We did not estimate pollen viability and thereby the success of hybrids as pollen donors. However, reciprocal crosspollinations between the wild, hybrid and cultivar types of our experiment showed no differences in compatibility among any combinations (LP Kiær, unpublished data). Considering the large number of capitulae and long flowering period, we speculate that hybrids also fathered a high proportion of seeds in the plot.

\section{Susceptibility to herbivory}

Despite availability of many wild-like roots, mice preferentially ate roots of cultivar-like and intermediate plants. Although this data set includes relatively few observations of herbivory, it is based on many plants, and the results support the hypothesis that hybrids between cultivated and wild plants could be more prone to herbivory (Cummings et al., 1999; Alexander et al., 2001). As the cultivar parents have been bred for palatability (Ryder, 1999), the hybrids may produce lower amounts of phytochemicals known to repel herbivores in chicory (Bais and Ravishankar, 2001). Also, higher nutrient concentrations in cultivar-like and hybrid roots may have made them more preferred (Zangerl and Bazzaz, 1992). A previous study on phenological, morphological and fitness-related traits of various European provenances of $C$. intybus also found large differences in root consumption by small rodents (Kollmann, personal communication).

\section{Hybrid fitness in wild populations}

We did not find evidence that hybrids were affected by outbreeding depression or hybrid breakdown. On the contrary, intermediate plants in the experimental plot on average produced more seeds than wild plants, including plants assigned to the second crossing generation $\left(\mathrm{F}_{2}\right.$ and backcrosses; results not shown). A number of intermediate plants actually produced extremely many seeds, and among these were the ones with the highest and the third and fourth highest seed production among all plants (Figure 3e). As with the morphological traits, hybrid seed production thus seems to be more variable than that of parental plants, as also suggested by Hails and Morley (2005). Transgression of parental fitness characters could thus lead to hybrids with a higher individual seed production than parental individuals, as also discussed by Hauser et al. (1998) in relation to second-generation hybrids between oilseed rape and Brassica rapa.

Our results could indicate that the seed production of hybrid plants may approach, or perhaps become lower, than that of wild plants in nutrient-poor habitats (Hails and Morley, 2005). In Denmark, natural populations of wild chicory only occur in the eastern part where the natural soil substrate is rich in clay and nutrients, and here mostly in roadsides, disturbed ruderal sites, and along beaches where nutrients are abundant. This suggests that the habitats of wild chicory could be suitable for hybrids, although they may be affected negatively by other biotic and abiotic factors as well. Many offspring plants in the experiment were at least second-generation hybrids exhibiting mixed leaf morphology, meaning that some of the plants in the roadside were also hybrids. The fact that chicory hybrids grew spontaneously in the densely vegetated roadside shows that they, at least sometimes, are able to survive and reproduce outside cultivated fields. Previously, van Cutsem et al. (2003) identified a number of feral populations of cultivar chicory established in ruderal sites. Hooftman et al. (2005) have shown that hybrids between lettuce (Lactuca sativa) and its wild progenitor Lactuca serriola (a close relative to chicory) can be well-fit even in densely vegetated natural habitats, and that they are able to establish hybrid selfing populations.

There seems to be no inherent fitness barrier to continued hybridization and thereby introgression between wild and cultivated chicory. This is also in accordance with recent studies showing that, despite intensive and prolonged breeding and adaptation of crops to cultivated habitats, and despite different morphologies and life histories, hybrids between cultivated and wild plants may sometimes be surprisingly vigorous and fertile (Hauser et al., 2003; Ellstrand, 2003b; Campbell et al., 2006).

\section{Conclusions}

We have demonstrated that hybrids of wild and cultivated chicories will be able to leave offspring for the next, more advanced hybrid generation. Over generations this may lead to introgression of cultivar genes into wild populations, unless the more advanced generations of hybrids suffer a dramatic fitness decline not detected in the present study.

Although the hybrids in our experiment were more prone to herbivory by mice than wild-like plants, only a relatively small proportion of the plants were killed, generally individuals that had not flowered. This may be different under conditions where more plants do not flower in their first year. The realized fitness of chicory hybrids will thus depend on factors such as prevalence of mice and other herbivores, ability of hybrids to reproduce in their first year, nutrient availability and whether the hybrids that produce many seeds are also the ones that are most eaten (due to association between genes coding for high seed production and low repelling of herbivores).

The consequence of hybridization between cultivated and wild chicory is most likely that cultivar genes, and among them transgenes, may introgress into wild populations, where the impact depends on the particular genes and their phenotypes. Genetic swamping and extinction of wild chicory populations may only rarely, if ever, be an issue, as chicory is cultivated for its vegetative structures. Flowering during seed production mostly takes place within tents, bolting plants in vegetative production fields are sporadic and most feral (wild) 
populations of cultivar chicory are probably small compared to the wild populations. The influx of cultivar genes to wild populations would thus be relatively small and probably lead to a sequence of backcrossing to wild plants. This would not create the intermediate hybrids and backcrosses to the crop that are necessary for genetic assimilation and extinction by outbreeding depression.

\section{Acknowledgements}

We thank RK Mannstaedt, NS Andersen and L Magnussen for helping with the morphological scorings, and NS Andersen, LG Nersting, MM Johannessen, C Damgaard, J Weiner, J Kollmann and E Gallandt for reviewing earlier drafts of the article and for help with language. Thanks to Bende Sørensen for kindly providing data on soil nutrients. Thanks also to K Pilegaard for providing the meteorological data. This work was supported by the EU-funded project ANGEL (QLTR-200001657).

\section{References}

Alexander HM, Cummings CL, Kahn L, Snow AA (2001). Seed size variation and predation of seeds produced by wild and crop-wild sunflowers. Am J Bot 88: 623-627.

Anderson EC, Thompson EA (2002). A model-based method for identifying species hybrids using multilocus genetic data. Genetics 160: 1217-1229.

Arnold ML (1997). Natural Hybridization and Evolution. Oxford University Press: New York.

Bais HP, Ravishankar GA (2001). Cichorium intybus L. cultivation, processing, utility, value addition and biotechnology, with an emphasis on current status and future prospects. J Sci Food Agr 81: 467-484.

Campbell LG, Snow AA, Ridley CE (2006). Weed evolution after crop gene introgression: greater survival and fecundity of hybrids in a new environment. Ecol Lett 9: 1198-1209.

Conner AJ, Glare R, Nap J-P (2003). The release of genetically modified crops into the environment, part II. Plant J 33: 19-46.

Cummings CL, Alexander HM, Snow AA (1999). Increased predispersal seed predation in sunflower crop-wild hybrids. Oecologia 121: 330-338.

De Vries FT, Van der Meijden R, Brandenburg WA (1992). Botanical files: a study of the real chances for spontaneous gene flow from cultivated plants to the wild flora of the Netherlands. Gorteria Suppl 1: 1-100.

Doyle JJ, Doyle JL (1987). A rapid DNA isolation procedure for small quantities of fresh leaf tissue. Phytochem Bull 19: 11-15.

Duchesne PL, Bernatchez L (2002). AFLPOP: a computer program for simulated and real population allocation based on AFLP data. Mol Ecol Notes 3: 380-383.

Eenink AH (1981). Compatibility and incompatibility in Witloof-Chicory (Cichorium intybus L). 2. The incompatibility system. Euphytica 30: 77-85.

Ellstrand NC (2003a). Dangerous Liaisons: When Cultivated Plants Mate with Their Wild Relatives. Johns Hopkins University Press: Baltimore.

Ellstrand NC (2003b). Current knowledge of gene flow in plants: implications for transgene flow. Phil Trans Biol Sci 358: 1163-1170.

Fanizza G, Damato G (1995). Analysis of seed yield components in chicory (Cichorium intybus L). J Appl Seed Prod 13: 22-24.

Frederiksen S, Rasmussen FN, Seberg O (eds) (2006). Dansk Flora. Gyldendal: Copenhagen.

Hails RS, Morley K (2005). Genes invading new populations: a risk assessment perspective. Trends Ecol Evol 20: 245-252.
Harrington JF, Verkerk K, Doorenbos J (1959). Interaction of vernalisation photoperiod and light intensity in floral initiation of endive. Neth J Agr Sci 7: 68-74.

Hauser TP, Bjørn GK (2001). Hybrids between wild and cultivated carrots in Danish carrot fields. Genet Res Crop Evol 48: 499-506.

Hauser TP, Damgaard C, Jørgensen RB (2003). Frequencydependent fitness of hybrids between oilseed rape (Brassica napus) and weedy B. rapa (Brassicaceae). Am J Bot 90: 571-578.

Hauser TP, Jørgensen RB, Stergård H (1998). Fitness of backcross and F2 hybrids between weedy Brassica rapa and oilseed rape (B. napus). Heredity 81: 436-443.

Haygood R, Ives AR, Andow DA (2003). Consequences of recurrent gene flow from crops to wild relatives. Proc Roy Soc Lond B Biol Sci 270: 1879-1886.

Hegde SG, Nason JD, Clegg JM, Ellstrand NC (2006). The evolution of California's wild radish has resulted in the extinction of its progenitors. Evolution 60: 1187-1197.

Hooftman DAP, Oostermeijer JGB, Jacobs MMJ, Den Nijs HCM (2005). Demographic vital rates determine the performance advantage of crop-wild hybrids in lettuce. J Appl Ecol 42: 1086-1095.

Johannessen MM, Mikkelsen TN, Jørgensen RB (2002). CO2 exploitation and genetic diversity in winter varieties of oilseed rape (Brassica napus); varieties of tomorrow. Euphytica 128: 75-86.

Kiers AM (2000). Endive, chicory and their wild relatives. A systematic and phylogenetic study of Cichorium (Asteraceae). Gorteria Suppl 5: 1-78.

Lai Z, Gross BL, Zou Y, Andrews J, Rieseberg LH (2006). Microarray analysis reveals differential gene expression in hybrid sunflower species. Mol Ecol 15: 1213-1227.

Lexer C, Welch ME, Raymond O, Rieseberg LH (2003). The origin of ecological divergence in Helianthus paradoxus (Asteraceae): selection on transgressive characters in a novel hybrid habitat. Evolution 57: 1989-2000.

Raybould AF, Gray AJ (1994). Will hybrids of genetically modified crops invade natural communities? Trends Ecol Evol 9: $85-89$.

Rhymer JM, Simberloff D (1996). Extinction by hybridization and introgression. Ann Rev Ecol Syst 27: 83-109.

Rick CM (1953). Hybridization between chicory and endive. Proc Am Soc Hort Sci 61: 459-466.

Ryder EJ (1999). Lettuce, Endive and Chicory (Crop Production Science in Horticulture 7). CABI Publishing: Oxfordshire.

Schittenhelm S (2001). Effect of sowing date on the performance of root chicory. Eur J Agron 15: 209-220.

Shim SI, Jørgensen RB (2000). Genetic structure in cultivated and wild carrots (Daucus carota L.) revealed by AFLP analysis. Theor Appl Getet 101: 227-233.

Van Cutsem P, du Jardin P, Boutte C, Beauwens T, Jacqmin S, Vekemans X (2003). Distinction between cultivated and wild chicory gene pools using AFLP markers. TAG 107: 713-718.

Van Dijk H (2004). Gene exchange between wild and crop in Beta vulgaris: how easy is hybridization and what will happen in later generations? In: den Nijs HCM, Bartsch D, Sweet J (eds). Introgression from Genetically Modified Plants into Wild Relatives. CABI Publishing: Wallingford. pp 53-62.

Vos P, Hogers R, Bleeker M, Reijans M, van de Lee T, Homes M et al. (1995). AFLP - a new technique for DNA-fingerprinting. Nucleic Acids Res 23: 4407-4414.

Wiebe HJ (1997). Causes of generative development of radicchio (Cichorium intybus var. foliosum). Gartenbauwissenschaft 62: 72-77.

Zangerl AR, Bazzaz FA (1992). Theory and pattern in plant defence allocation. In: Fritz RS, Simms EL (eds). Plant Resistance to Herbivores and Pathogens. University of Chicago Press: Chicago. pp 363-391.

Zhivotovsky LA, Christiansen FB (1995). The selection barrier between populations subject to stabilizing selection. Evolution 49: 490-501. 